\title{
Manufacturing and Leak Check of Shell Targets for the FIREX-I Project
}

\author{
Takeshi FUJIMURA, Mitsuo NAKAI, Akifumi IWAMOTO1), Keiji NAGAI ${ }^{\mathrm{a})}$, \\ Hirofumi HOMMA, Ken-ichi TANABE and Takayoshi NORIMATSU \\ Institute of Laser Engineering (ILE), Osaka University, 2-6 Yamada-oka, Osaka 565-0871 Japan \\ ${ }^{1)}$ National Institute for Fusion Science (NIFS), 322-6 Oroshi-cho, Toki, Gifu 509-0292, Japan
}

(Received 3 March 2009 / Accepted 3 June 2009)

\begin{abstract}
This article reports the latest progress in the manufacture of shell targets used for the first stage of the Fast Ignition Realization Experiment (FIREX-I). In the project, the targets are cooled to cryogenic temperature and filled with hydrogen isotope fuel through a gas feed tube. If the target has a leak or the gas feeder is blocked, the experiments cannot be carried out successfully and waste much time. The authors have developed a system to check integrity of the targets. $\mathrm{SF}_{6}$ is used instead of $\mathrm{H}_{2}$ or $\mathrm{D}_{2}$ because of its high refractive index and low diffusivity. When $\mathrm{SF}_{6}$ is loaded into the target, the optical path length that passes through a target is longer than that of an evacuated target. The difference can be measured with an interferometer. Analyzing the interference images, it is possible to know whether the gas feeder is blocked and a leak is present. The validity of the system was experimentally confirmed.
\end{abstract}

(C) 2009 The Japan Society of Plasma Science and Nuclear Fusion Research

Keywords: target fabrication, leak check, cryogenic target, fast ignition, laser fusion, interferometer

DOI: $10.1585 /$ pfr.4.S1010

Laser fusion is a promising candidate as a future energy source. Fast Ignition (FI) can achieve high gain [1]. FI has been studied cooperatively by the Institute of Laser Engineering (ILE) and the National Institute for Fusion Science (NIFS); ILE and NIFS are working on the first stage of Fast Ignition Realization Experiment (FIREX-I). A unique target for FIREX-I has been designed [2]. The target consists of three parts: a shell, a laser guide cone, and a gas feeder. The plastic shell is made of polystyrene foam or other low density materials [3]. In a low density foam target, the foam is covered by poly( $p$-xylylene). These parts are bonded together with epoxy resin. Many problems remain in the manufacture of these targets, for instance, leakage of the gas feed. Because the target is small, precise handling is difficult. Leakage will occur when there is too little resin, and the gas feeder will be blocked when epoxy resin sticks to the tip of the gas feeder. This letter presents a proposal for manufacturing and checking the soundness of the targets.

The shells are $500 \mu \mathrm{m}$ in diameter and are made using a triple-orifice droplet generator [4]. When a shell is made of low density foam, it is coated with a poly ( $p$-xylylene) gas barrier using chemical vapor deposition. The gold laser guide cone is made by plating. The angle of the cone tip is 30 degrees. The gas feeder is made of glass. A narrow glass tube (outer diameter $30 \mu \mathrm{m}$ ) is bent by heating. The gas feeder is bonded by epoxy resin alongside the guide

author's e-mail: t-fujimura@ile.osaka-u.ac.jp

a) Present address; Chemical Resources Laboratory, Tokyo Institute of Technology, 226-8503 Yokohama, Japan cone, in a position that is more than $300 \mu \mathrm{m}$ from the tip of the guide cone. A small area of the shell is dissolved by toluene to make a hole, and then the gas feeder and the guide cone are inserted into the hole using manipulators. After that, the boundary between the cone and shell is sealed by an epoxy resin-saturated paper string.

The quantity of leakage $Q_{\text {leak }}$ from a target is expressed as

$$
Q_{\text {leak }}=Q_{\text {total }}-Q_{\text {permeation }}
$$

where $Q_{\text {total }}$ is the total decrease in quantity inside the target and $Q_{\text {permeation }}$ is a decrease of the quantity by permeation. The volume is the same, i.e.,

$$
\mathrm{d} P_{\text {leak }}=\mathrm{d} P_{\text {total }}-\mathrm{d} P_{\text {permeation }}
$$

where $\mathrm{d} P$ is the change in the pressure inside the target.

A simple system, used at room temperature, was developed to check leakage and the integrity of the structure. The permeation rate of $\mathrm{H}_{2}$ at room temperature is too high to measure leakage from the shell; we therefore used $\mathrm{SF}_{6}$ gas in this experiment. The molecular weight of $\mathrm{SF}_{6}$ gas is high, keeping its permeation rate low. $\mathrm{SF}_{6}$ gas has a high refractive index [5] and is not corrosive.

The permeation rate of $\mathrm{SF}_{6}$ gas through a polystyrene sheet and poly ( $p$-xylylene) was measured. Figure 1 shows the measuring system. Two chambers are separated by a sample sheet.

The samples are polystyrene and poly( $p$-xylylene) sheets. First, both chambers were evacuated and the 


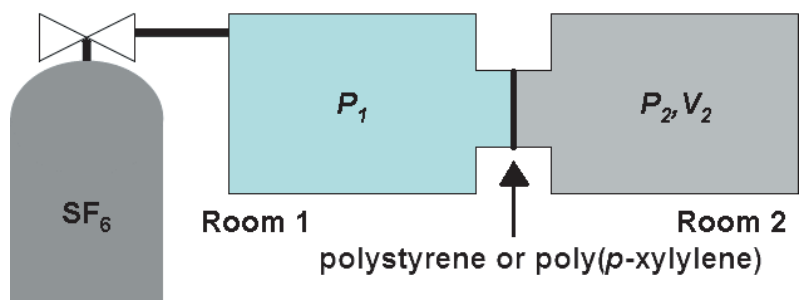

Fig. 1 A schematic view of experimental set-up for measuring a permeation rate.

Table 1 Permeation rates $\left(10^{-16} \mathrm{~Pa} / \mathrm{mol} \cdot \mathrm{sec} \cdot \mathrm{m}\right)$

\begin{tabular}{lccc}
\hline & Average & minimum & maximum \\
\hline Polystyrene & 2.6 & 0.36 & 5.5 \\
Poly $(p$-xylylene $)$ & 9.5 & 0.76 & 22 \\
\hline
\end{tabular}

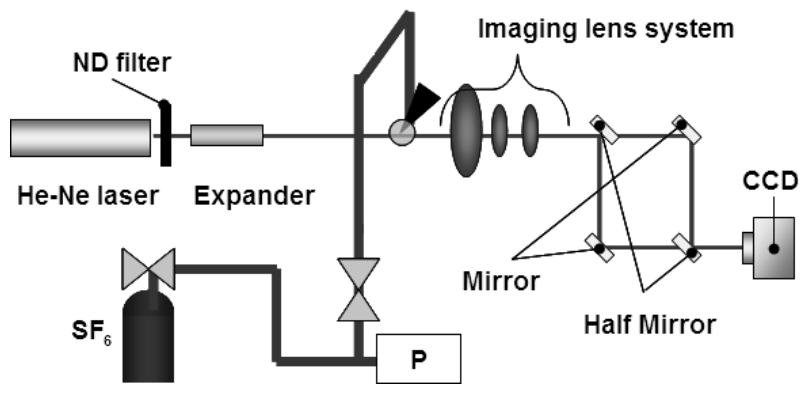

Fig. 2 A schematic view of an experimental setup for the interferometer.

pressure of chamber 2 was monitored for $20 \mathrm{~min}$. Then chamber 1 was loaded with $\mathrm{SF}_{6}$ gas. The pressure of room 2 was measured for $20 \mathrm{~min}$. The permeation rate $q(\mathrm{~Pa} / \mathrm{mol} \cdot \mathrm{sec} \cdot \mathrm{m})$ is calculated approximately as

$$
q=\frac{P_{2} \cdot t \cdot R \cdot T}{P_{1} \cdot \tau \cdot S \cdot V_{2}}
$$

where $P_{1}$ and $P_{2}$ are the differential pressures, $t$ is the thickness; $S$ is the area of sample sheets, $\tau$ is time, $R$ is the gas constant, and $T$ is the temperature.

Permeation rates of nine samples of polystyrene and five samples of poly( $p$-xylylene) were measured. Table 1 shows average, minimum, and maximum values of the two materials.

To measure the total decrease of pressure from a shell, a Mach-Zehnder interferometer was used (Fig. 2). A $\mathrm{He}-\mathrm{Ne}$ laser of $633 \mathrm{~nm}$ wavelength was used as the light source. The imaging lens system expands and transfers the interference image to a CCD camera. After evacuation, a target was loaded with $\mathrm{SF}_{6}$ up to $0.2 \times 10^{6} \mathrm{~Pa}$. Interference images were taken before and after pressurizing $\mathrm{SF}_{6}$ to confirm that the gas feeder was not blocked.

Figures 3 show interference images; Fig. 3 (a) was taken after evacuation. Comparing Figs. 3 (a) and (b), the

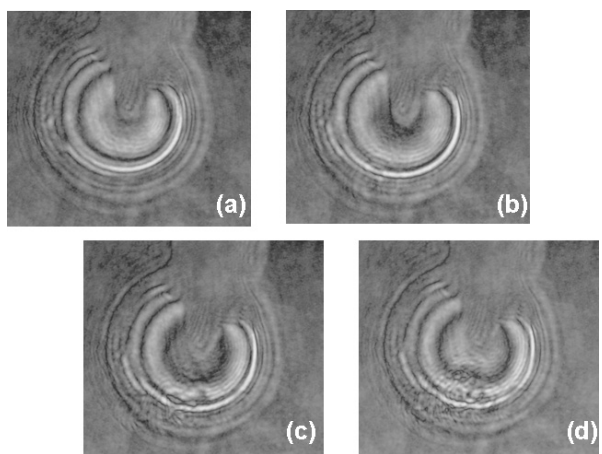

Fig. 3 (a) Interference images of a vacant polystyrene shell target. (b) $0.2 \mathrm{MPa}$ of $\mathrm{SF}_{6}$ gas was fed into the shell. (c) and (d) are at 6 and 12 mins after feeding $\mathrm{SF}_{6}$ gas.

different fringe patterns of the interference images are visible, meaning that the gas feeder is not blocked. After feeding $\mathrm{SF}_{6}$ gas (Fig. 3 (b)), the interference image was observed for $12 \mathrm{~min}$ without further supplying gas into the shell. In Fig. 3(b), the center of the shell is dark, whereas in Fig. 3(d), it is bright. This means that the optical path length was shifted $1 / 2$ wavelength during the $12 \mathrm{~min}$, which corresponded to a decrease in the pressure of $\mathrm{SF}_{6}$ of $0.8 \times 10^{5} \mathrm{~Pa}$. The $\mathrm{d} P_{\text {permeation }}$ of this shell was calculated using Eq. (3) and the average value of polystyrene shown in Table 1.

The size of the leak hole on the shell was estimated as follows: $\mathrm{d} P$ permeation is $3.0 \mathrm{~Pa}$ for $12 \mathrm{~min}$ and can be ignored. From Eq. (1), it is assumed that $\mathrm{d} P_{\text {total }} \approx \mathrm{d} P_{\text {leak }}$; thus, $\mathrm{d} P_{\text {leak }}$ is expressed as

$$
\mathrm{d} P_{\text {leak }}(t)=P_{2}(0)-P_{2}(t)
$$

where $P_{2}(t)=P_{1}(t)-P_{0}, P_{1}(t)$ is the pressure in the shell and $P_{0}$ is atmospheric pressure; [6] $P_{2}(t)$ is a time function

$$
P_{2}(t)=P_{2}(0) \exp \left(-\frac{C}{V} t\right)
$$

where $V$ is volume. This flow is a viscous flow. If the leak hole is assumed to be columnar, the conductance $C$ is

$$
C=1349 \frac{d^{4}}{L} P_{3},
$$

where $d$ and $L$ (thickness of the shell $=5.0 \mu \mathrm{m}$ ) are diameter and length, $P_{3}$ is $\left(P_{1}+P_{2}\right) / 2$ [6]. When $d=6.3 \mu \mathrm{m}$, $\mathrm{d} P_{\text {leak }}=0.8 \times 10^{5} \mathrm{~Pa}$ for $12 \mathrm{~min}$. Therefore, this system is capable of detecting a hole with a diameter of $6.3 \mu \mathrm{m}$.

This letter describes a way to manufacture targets, check for leakage, and determine if the gas feeder is blocked. It was possible to detect a hole with a diameter of $6.3 \mu \mathrm{m}$.

This work was supported by Research Fellowships of the Japan Society for the Promotion of Science for Young Scientists. 
[1] H. Azechi and the FIREX Project, Plasma Phys. Control. Fusion 48, B267 (2006).

[2] T. Norimatsu et al., Fusion Sci. Technol. 43, 339 (2003).

[3] F. Ito et al., Jpn. J. Appl. Phys. B 45, L335 (2006).

[4] S.M. Lambert et al., J. Appl. Poly. Sci. 65, 2111 (1997).
[5] http://www.agc.co.jp/products/chemical/sf6_3.html (in Japanese)

[6] S. Yoshikawa, Sinnkuu handobukku (in Japanese) (ULVAC, Japan, 1989) p.36. 